Supplement of Biogeosciences, 14, 4815-4827, 2017

https://doi.org/10.5194/bg-14-4815-2017-supplement

(C) Author(s) 2017. This work is distributed under

the Creative Commons Attribution 3.0 License.

(c) (1)

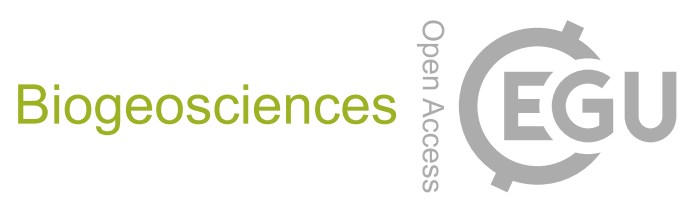

Supplement of

\title{
Contrasting effects of ammonium and nitrate additions on the biomass of soil microbial communities and enzyme activities in subtropical China
}

Chuang Zhang et al.

Correspondence to: Xin-Yu Zhang (zhangxy@igsnrr.ac.cn) and Hong-Tao Zou (zouhongtao2001@163.com)

The copyright of individual parts of the supplement might differ from the CC BY 3.0 License. 


\section{$1 \quad$ Supplementary materials}

2

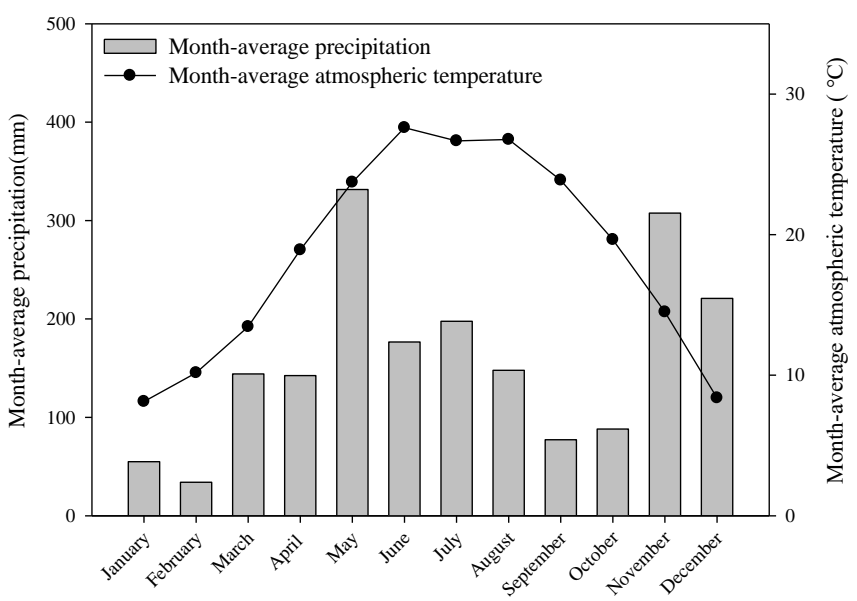

$4 \quad$ Fig S1. Average monthly atmospheric temperature and precipitation at the study site during 2015. 


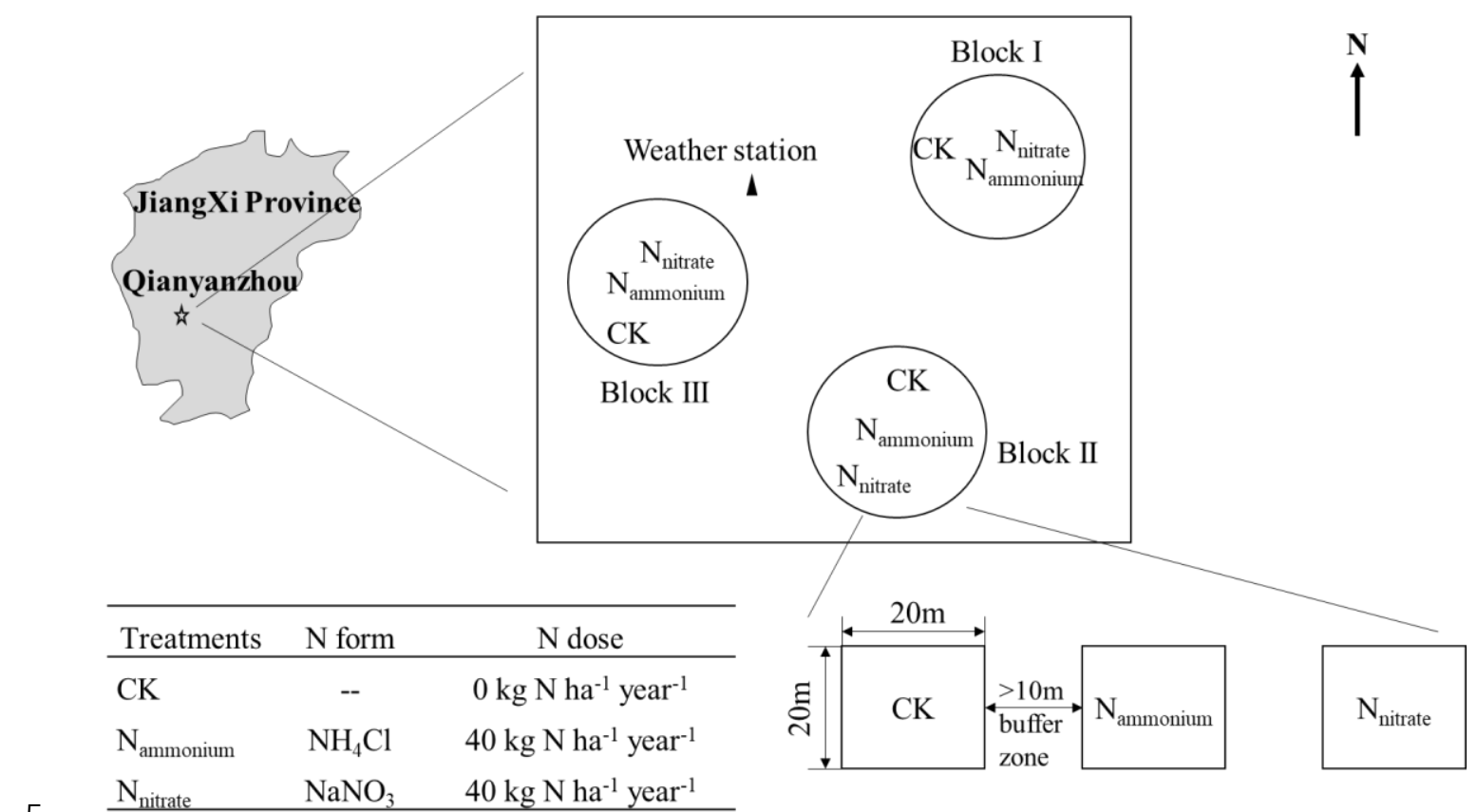

6 Fig S2. The schematic diagram of the experimental treatments. 
Table S 1 Enzymes and their corresponding substrates and functions.

\begin{tabular}{|c|c|c|c|c|}
\hline Enzyme & Ec & $\begin{array}{l}\text { Abbrevia } \\
\text { tion }\end{array}$ & Substrate & Function \\
\hline Peroxidase & 1.11 .1 .7 & PER & L-DOPA & $\begin{array}{l}\text { Oxidize lignin and aromatic compounds using } \mathrm{H}_{2} \mathrm{O}_{2} \\
\text { or secondary oxidants as an electron acceptor }\end{array}$ \\
\hline Phenol oxidase & 1.10 .3 .2 & $\mathrm{PPO}$ & L-DOPA & $\begin{array}{l}\text { Oxidize phenolic compounds using oxygen as an } \\
\text { electron acceptor }\end{array}$ \\
\hline$\alpha$-1,4-glucosidase & 3.2 .1 .20 & $\alpha \mathrm{G}$ & 4-MUB- $\alpha$-D-glucoside & Releases glucose from starch \\
\hline$\beta$-1,4-glucosidase & 3.2.1.21 & $\beta G$ & 4-MUB- $\beta$-D-glucoside & Releases glucose from cellulose \\
\hline Cellobiohydrolase & 3.2 .1 .91 & $\mathrm{CBH}$ & 4-MUB- $\beta$-D-cellobioside & Releases disaccharides from cellulose \\
\hline$\beta$-1,4-xylosidase & 3.2.1.37 & $\beta X$ & 4-MUB- $\beta$-D-xyloside & Releases xylose from hemicellulose \\
\hline $\begin{array}{c}\beta-1,4-\mathrm{N}- \\
\text { acetylglucosaminidase }\end{array}$ & 3.2 .1 .14 & NAG & $\begin{array}{l}\text { 4-MUB-N-acetyl- } \beta \text {-D- } \\
\text { glucosaminide }\end{array}$ & $\begin{array}{l}\text { Releases N-acetyl glucosamine from } \\
\text { oligosaccharides }\end{array}$ \\
\hline Acid phosphatase & 3.1.3.1 & $\mathrm{AP}$ & 4-MUB-phosphate & Releases phosphate groups \\
\hline
\end{tabular}


8 Table S2 Time-independent seasonal variations in ammonium and PLFAs. Small letters represent

9 significant differences between the sampling time $(P<0.05)$, error bars represent means \pm standard errors

$10(n=9)$.

\begin{tabular}{ccccc}
\hline Months & $\begin{array}{c}\text { Ammonium } \\
\mathrm{mg} \mathrm{kg}^{-1}\end{array}$ & $\begin{array}{c}\text { Total PLFA } \\
\mathrm{nmol} \mathrm{g}^{-1}\end{array}$ & $\begin{array}{c}\text { Bacteria } \\
\mathrm{nmol} \mathrm{g}^{-1}\end{array}$ & $\begin{array}{c}\mathrm{G}^{-} \\
\mathrm{nmol} \mathrm{g}^{-1}\end{array}$ \\
\hline March & $23.5 \pm 1.0 \mathrm{a}$ & $9.2 \pm 0.2 \mathrm{c}$ & $7.1 \pm 0.2 \mathrm{c}$ & $2.5 \pm 0.1 \mathrm{c}$ \\
June & $10.6 \pm 1.0 \mathrm{~b}$ & $11.0 \pm 0.2 \mathrm{~b}$ & $7.7 \pm 0.2 \mathrm{~b}$ & $3.1 \pm 0.1 \mathrm{~b}$ \\
October & $7.5 \pm 1.0 \mathrm{~b}$ & $16.7 \pm 0.2 \mathrm{a}$ & $13.8 \pm 0.2 \mathrm{a}$ & $5.0 \pm 0.1 \mathrm{a}$ \\
\hline
\end{tabular}

11 